\title{
IL-17 and VEGF Are Necessary for Efficient Corneal Nerve Regeneration
}

\author{
Zhijie Li, ${ }^{* \dagger}$ Alan R. Burns, ${ }^{* \ddagger}$ Lei Han ${ }^{\star \S}$ \\ Rolando E. Rumbaut, ${ }^{* \Uparrow \|}$ and C. Wayne Smith*\| \\ From the Section of Leukocyte Biology, "Department of Pediatrics, \\ and the Department of Medicine," Baylor College of Medicine, \\ Houston, Texas; the Key Laboratory for Regenerative Medicine of \\ Ministry of Education and Department of Ophthalmology, Jinan \\ University, Guangzhou City, China; the College of Optometry, ${ }^{*}$ \\ University of Houston, Houston, Texas; the Henan Eye Institute \\ and Henan Province Hospital, ${ }^{\S}$ Zhengzhou City, China; and the

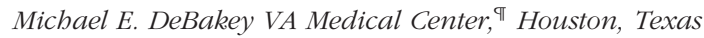

The contribution of acute inflammation to sensory nerve regeneration was investigated in the murine cornea using a model of corneal abrasion that removes the stratified epithelium and subbasal nerve plexus. Abrasion induced accumulation of $\mathrm{IL}_{-1} 7^{+}$ $\mathrm{CCR}^{+} \gamma \delta \mathrm{T}$ cells, neutrophils, and platelets in the cornea followed by full restoration of the epithelium and $\sim 19 \%$ regeneration of sensory nerves within 96 hours. Mice deficient in $\gamma \delta$ T cells $\left(\operatorname{TCR} \delta^{-/-}\right)$or wildtype mice treated systemically with anti-IL-17 had $>50 \%$ reduction in leukocyte and platelet infiltration and $>50 \%$ reduction in nerve regeneration. Strategies used to prevent neutrophil and platelet accumulation (eg, wild-type mice treated with anti-Ly6G or antiGP1b $\alpha$ antibody to deplete neutrophils or platelets) also resulted in $>50 \%$ reductions in corneal nerve density. Infiltrating neutrophils and platelets stained positively for VEGF-A, tissue levels of VEGF-A peaked coincidentally with peak tissue levels of neutrophils and platelets, depletion of neutrophils before injury reduced tissue VEGF-A levels by $>70 \%$, and wild-type mice treated systemically with anti-VEGF-A antibody exhibited $>80 \%$ reduction in corneal nerve regeneration. Given the known trophic effects of VEGF-A for neurite growth, the results in this report demonstrate a previously unrecognized beneficial role for the $\gamma \delta \mathrm{T}$ cell-dependent inflammatory cascade involving IL17, neutrophils, platelets, and VEGF-A in corneal nerve regeneration. (Am J Pathol 2011, 178:1106-1116; DOI: 10.1016/j.ajpath.2010.12.001)

Although acute inflammation is critical for host defense against infection, extravasating leukocytes typically induce some tissue injury and may delay wound healing. ${ }^{1}$ However, direct contribution of acute inflammation to nerve regeneration has been implicated in recent studies of spinal cord injury. ${ }^{2}$ Infiltrating leukocytes appear to be central to this beneficial effect, though mechanisms remain undefined. In the current paper, we examine contributions of acute inflammation to nerve regeneration in the cornea, a tissue highly vulnerable to nerve damage. Corneal epithelium has an abundance of sensory nerves arrayed in a dense plexus just beneath the basal epithelial layer. ${ }^{3-5} \mathrm{Nu}$ merous epithelial branches containing nociceptors penetrate the stratified epithelium reaching near the epithelial surface. Superficial corneal wounds can readily damage the subbasalar nerves, thereby reducing important sensory functions and, possibly, trophic effects of these nerves that sustain integrity of the corneal epithelium. ${ }^{6-8}$

In animal models, corneal wounds induce influx of inflammatory cells that migrate through the avascular corneal stroma from the limbal vessels to the wound site. Neutrophils are most abundant, ${ }^{9}$ and macrophages, dendritic cells, and lymphocytes are also evident. ${ }^{9-12}$ Inflammatory cells also increase in the epithelium surrounding the wound, with $\gamma \delta$ T cells and macrophages being most common and neutrophils rarely seen within the epithelium. ${ }^{11,13,14} \gamma \delta \mathrm{T}$ cells have been shown to participate in wound healing of epithelial surfaces of the skin, gastrointestinal track, and lung, ${ }^{15,16}$ and we have recently shown they contribute to epithelial healing of the cornea. ${ }^{11,14}$ In some locations, $\gamma \delta$ T cells are responsible for significant influx of neutrophils, an effect linked to $\gamma \delta \mathrm{T}$ cell-derived IL-17 (eg, peritoneal exudate following injection of microbial products). ${ }^{17,18}$ In other locations, $\gamma \delta$ T cells seem to have little influence on neutrophil influx, eg, dermal wounding. ${ }^{19,20}$ It is now evident that $\gamma \delta \mathrm{T}$ cells contribute cytokines, chemokines, and growth factors in early phases of tissue injury or infection functioning as key participants in the innate immune response activated through $\mathrm{T}$ cell receptor (TCR) ligand recognition or innate pattern recognition receptors such as TLR2, AhR, or nectin-1. ${ }^{16,21-23}$ Although their

Supported by National Institutes of Health grants EY018239, EY017120, and EY007551; National Natural Science Foundation of China grants 30672287, 30772387, and 81070703; and a Merit Review grant from the Department of Veterans Affairs.

Accepted for publication December 1, 2010.

Address reprint requests to C. Wayne Smith, M.D., Section of Leukocyte Biology, Children's Nutrition Research Center, Department of Pediatrics, Baylor College of Medicine, 1100 Bates, Rm 6014, Houston, TX 77030. E-mail: cwsmith@bcm.tmc.edu. 

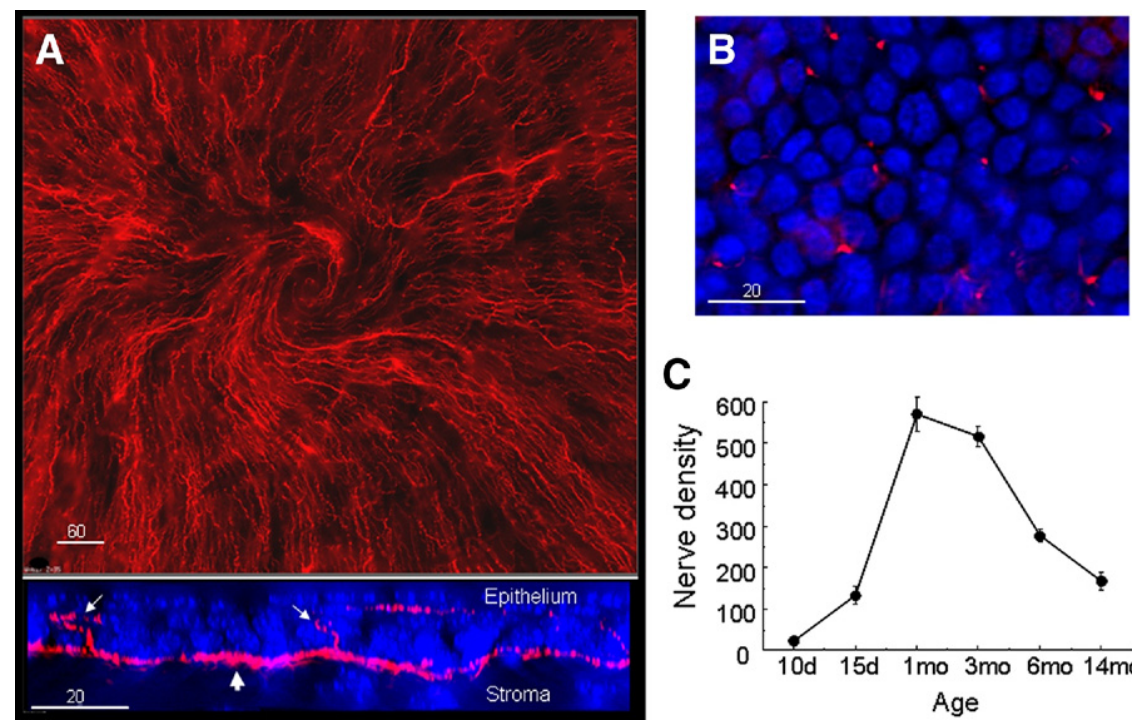

Figure 1. Nerve density in unwounded corneas. A: Upper panel is a montage showing subbasal nerve patterns typical of the central cornea in male C57BL/ 6 mice 3 months of age (anti-tubulin III-PE staining). The lower panel shows an orthogonal view generated from a deconvolved $30-\mu$ m-deep $z$-stack collected a $0.5-\mu \mathrm{m}$ steps revealing the positional relationship between basal epithelial nuclei (blue,

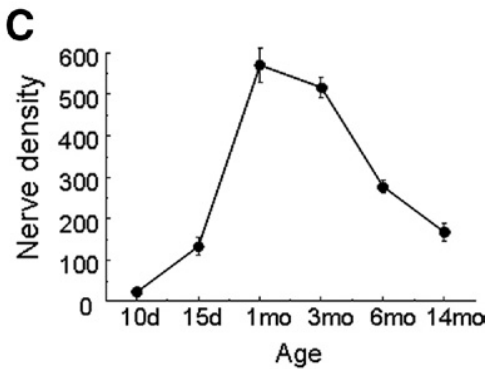
DAPI), subbasal nerves (red, anti-tubulin III, large arrow) and epithelial branches from the subbasal nerves (small arrows). B: En face view of the corneal epithelium where epithelial branches from subbasal nerves (anti-tubulin III$\mathrm{PE}$, red) are seen at the focal plane of basal epithelial nuclei. C: Age-dependent differences in the number of corneal epithelial nerve branches expressed as the sum of counts in seven fields across the cornea (see schema of morphometric analysis in Figure 2B).

importance is evident in epithelial healing, their role in nerve regeneration has not been analyzed.

In the current paper, we investigate the recovery of corneal nerves after epithelial abrasion that removes a region of the subbasalar nerve plexus. We demonstrate that deficiency of $\gamma \delta \mathrm{T}$ cells significantly retards nerve regeneration and provide evidence that $\mathrm{CCR}^{+} \mathrm{IL}^{-1} 7^{+}$ $\gamma \delta \mathrm{T}$ cells and IL-17 are necessary for early neutrophiland platelet-dependent delivery of VEGF-A, a trophic factor for neurite generation.

\section{Materials and Methods}

\section{Animals}

$\mathrm{TCR} \delta^{-1-}$ mice on the C57BL/6 background and C57BL/6 mice were purchased from the Jackson Laboratory (Bar Harbor, ME). Intercellular adhesion molecule (ICAM)$1^{-1-}$ mice $^{24,25}$ and P-selectin ${ }^{-1-}\left(\mathrm{P}_{-} \mathrm{sel}^{-1-}\right)$ mice ${ }^{11}$ were backcrossed on the C57BL/6 background as described. All animals were bred and housed in our facility according to the guidelines described in the Association for Research in Vision and Ophthalmology Statement for the Use of Animals in Vision and Ophthalmic Research and Baylor College of Medicine Animal Care and Use Committee policy. Mice were controlled for sex (male) and age (2 to 3 months, a time of peak corneal nerve density) (Figure 1). To deplete neutrophils or platelets, mice were injected intraperitoneally with anti-mouse Ly-6G (clone 1A826; BD Pharmingen, San Diego, CA) or anti-mouse GPIb $\alpha$ (Emfret Analytics, Würzburg, Germany) with 0.1 $\mathrm{mg}$ in $200 \mu \mathrm{l}$ of PBS 24 hours before wounding. ${ }^{27}$ Some mice were depleted of $\gamma \delta \mathrm{T}$ cells as previously described ${ }^{11,14}$ by intraperitoneal injection of $200 \mu \mathrm{g}$ of hamster anti-TCR $\gamma \delta$ monoclonal antibody (clone GL3 ${ }^{28}$; BD Pharmingen $)$ in a volume $(0.30 \mathrm{ml})$ of sterile PBS before or 14 hours following corneal abrasion. Sham depletion was accomplished with hamster immunoglobulin (Jackson Laboratory). Passive transfer of isolated platelets was as previously described. ${ }^{27}$ For neutralization of VEGF-A and
$\mathrm{IL}-17$, a single dose of $200 \mu \mathrm{g}$ of anti-mouse VEGF-A polyclonal IgG (Biolegend, San Diego, CA), ${ }^{29}$ and 100 $\mu \mathrm{g}$ of anti-mouse IL-17A mAb (clone TC11-18H10.1; Biolegend) ${ }^{30}$ or rat IgG1 isotype (Jackson ImmunoResearch Lab, West Grove, PA) in $0.3 \mathrm{ml}$ of PBS were intraperitoneally administrated before wounding, respectively. For IL-17 replacement in $\mathrm{TCR} \delta^{-1-}$ mice, a single dose of $1000 \mathrm{ng}$ of recombinant IL-17 (R\&D Systems, Minneapolis, MN) in 0.3 ml PBS was intraperitoneally injected. ${ }^{31}$ To analyze the local effect of VEGF and IL-17 on corneal inflammation or nerve regeneration after wounding, some mice received antimouse VEGF or anti-IL-17 goat polyclonal antibody (200 $\mu \mathrm{g} / \mathrm{ml}$; R\&D Systems) dissolved in lubricating eye drops (AdvancedMedical Optics, Santa Ana, CA) every 4 hours for 24 hours. The control animals received an equal concentration of goat lgG solution as eye drops.

\section{Corneal Epithelial Wounding Model}

The central corneal wound was performed as previously described ${ }^{14}$ using a 2-mm trephine to delineate the area to be removed using a golf club spud for refractive surgery (Accutome, Malvern, PA) under a dissecting microscope. At various times following injury, mice were euthanized, and corneal tissue including the limbus was excised and processed for immunohistology or mRNA isolation.

\section{Immunofluorescence and Deconvolution Imaging}

The corneal whole-mount technique was as described before. ${ }^{14}$ In brief, wounded corneas with the complete limbus were dissected, fixed ( $2 \%$ formaldehyde), permeabilized (0.01\% Triton X-100), and then incubated with the following labeled monoclonal antibodies: anti-TCR $\delta$ PE or FITC (clone GL3; BD Pharmingen) and anti-TCR $\delta$ APC (clone Gl3; eBiosciences, San Diego, CA) for $\gamma \delta \mathrm{T}$ cells; PECAM-1 (MEC 13.3 clone; BD Pharmingen) for limbal vessel endothelium; anti-Gr-1 (RB6-8C5 clone; BD Pharmingen) for neutrophils; anti-mVEGF (Lot No:YU14; 

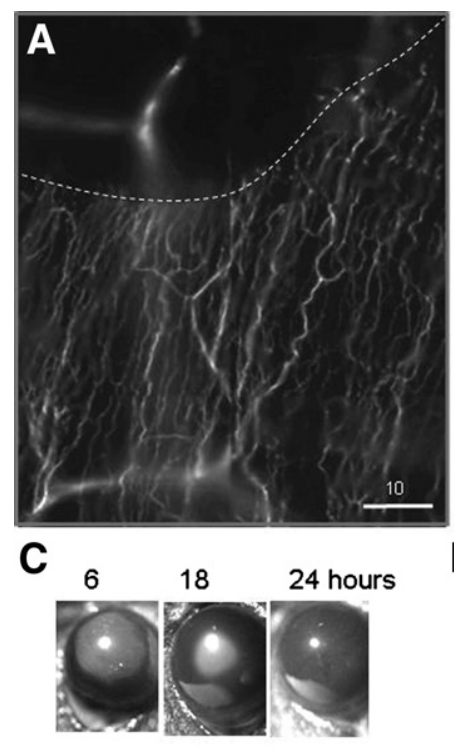

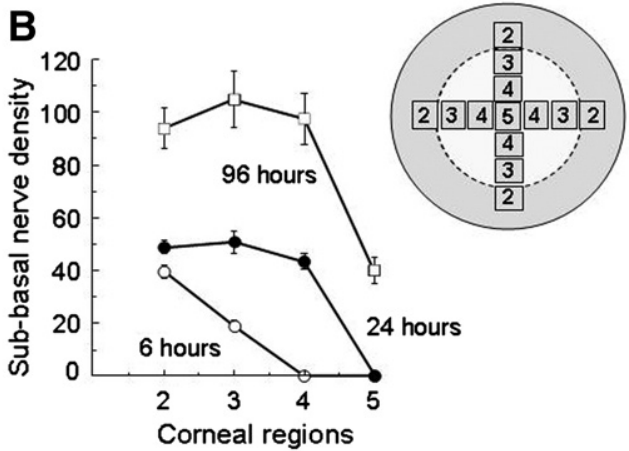

96 hrs after abrasion

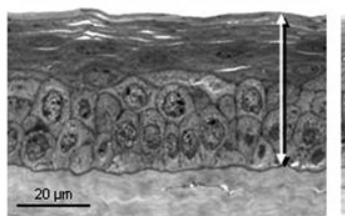

Uninjured

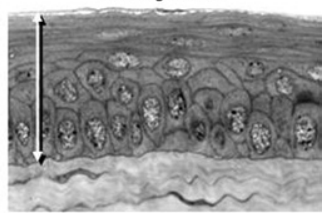

Figure 2. Regeneration of corneal nerves after central epithelial abrasion. A: Image of anti-tubulin III-stained cornea immediately after central abrasion showing loss of nerves in the abraded area An out-of-focus stromal nerve fiber is seen beneath the abraded area. The dashed line indicates the limit of the epithelial abrasion. B: Plot of pointcounting density of subbasal nerves in corneal regions from the wound margin (field 2) to the center of the original abrasion (field 5) at different times after epithelial abrasion $(n=4, P<0.01$ for time). Inset shows a schematic view of the cornea with fields $(150 \times 150 \mu \mathrm{m})$ relative to the abraded area (enclosed by dotted line) analyzed by point counting. This pattern was used for morphometric analysis in subsequent figures presenting data on mean nerve densities in fields from the paralimbal field 2 to the center of the cornea (field 5). C: Typical images of wound closure showing the abraded area (fluorescein stained) of the corneal surface with partial and complete closure from 6 to 24 hours. D: Cross sections of the central corneal epithelium at 96 hours following abrasion compared with an uninjured cornea of age- and sex-matched control. Full thickness of the stratified epithelium is indicated by the arrows.
R\&D Systems) for intracellular VEGF-A; anti-CD41 (MWReg30 clone; BD Pharmingen) for platelets; antitubulin $\beta$ III (TuJ-1 clone; R\&D Systems) for corneal nerves; anti-mouse IL-17A PE (clone eBio17B7; eBiosciences); and anti-mouse CCR6 FITC (clone 140706; eBiosciences), respectively. Controls using IgG isotype serum were in all cases negative. Radial cuts were made in the cornea so that it could be flattened by a coverslip, and the cornea was mounted in Airvol (Celanese, Ltd, Dallas, TX), containing $1 \mu \mathrm{mol} / \mathrm{L}$ of DAPI (Sigma Chemical, St. Louis, MO) to assess nuclear morphology. Image analysis and quantification of wounded corneas were performed using Delta Vision (Applied Precision, Issaquah, WA) as previously described. ${ }^{14}$ For documentation of corneal nerve regeneration, subbasal nerve density was assessed using a standard pattern (see Figure 2B) for morphometric analysis. ${ }^{14}$ Whole mounts were evaluated using $\times 40$ oil immersion lens to assess each field of view $(150 \times 150 \mu \mathrm{m})$ across the cornea from limbus to limbus. Each field was digitally captured for analysis as a projected image of a 30- $\mu \mathrm{m}$-deep, deconvolved z-stack (0.5- $\mu \mathrm{m}$ steps) encompassing the corneal epithelium, the subbasal nerves plexus, and an adjacent portion of the corneal stroma. Systematic, uniform random sampling was used to avoid observer sampling bias. Digital images of tubulin III-positive nerve fibers within the field were analyzed in Adobe Photoshop (Adobe Systems Inc., San Jose, CA) using a standard point-counting grid to obtain estimates of subbasal and epithelial nerve density. Counting was done by a blinded observer. For analysis of platelets in the limbus of healing corneas, eight randomly sampled fields (projected images of a 30- $\mu \mathrm{m}$-deep z-stack, $0.5-\mu \mathrm{m}$ steps, encompassing the limbal vessels) were collected from the limbus of each cornea stained with anti-CD31 to label limbal vessels and with anti-CD41 to label platelets. All platelets in the fields were counted and divided into those overlying the vessels and those not overlying the vessels (ie, platelets judged to be in the extravascular compartment).

\section{Histological Assessment of Corneal Epithelial Thickness}

Enucleated eyes were fixed overnight at $4^{\circ} \mathrm{C}$ in $0.1 \mathrm{M}$ sodium cacodylate buffer ( $\mathrm{pH} 7.2$ ) containing $2.5 \%$ glutaraldehyde. The cornea was then excised, taking care to include the limbal tissue, and postfixed in $1 \%$ osmium tetroxide for 1 hour at room temperature, dehydrated through an ethanol series, and then embedded in resin (LX 112; Polysciences, Warrington, PA). Thick (0.5- $\mu \mathrm{m})$ sections were cut on an ultramicrotome (RMC 7000; Venana Medical Systems, Tucson, AZ) equipped with a diamond knife. Sections were stained with toluidine blue $\mathrm{O}$ and viewed on an inverted microscope (DeltaVision Spectris; Applied Precision) using a $\times 20$ objective, and transverse measurements of the central epithelial thickness were made using the calibrated linear measurement tool contained in the supplied imaging software (SoftWorx).

\section{VEGF ELISA Assay}

VEGF was analyzed by ELISA kit (R\&D Systems) in extracts of corneas collected at 0, 6, 12, 18, 24, 48, and 96 hours after wounding. Six corneas at each time point were pooled in $400 \mu \mathrm{l}$ of PRIM-1640 medium and subjected to three freeze-thaw cycles and sonication for 30 seconds at $250 \mathrm{~Hz}$. All homogenates were frozen at $-70^{\circ} \mathrm{C}$ until they were used in the assay.

\section{Statistical Analysis}

Data analysis was performed using analysis of variance and pairwise multiple comparisons using Tukey's test. A $P$ value of $<0.05$ was considered significant. Data are expressed as means \pm SEM. 

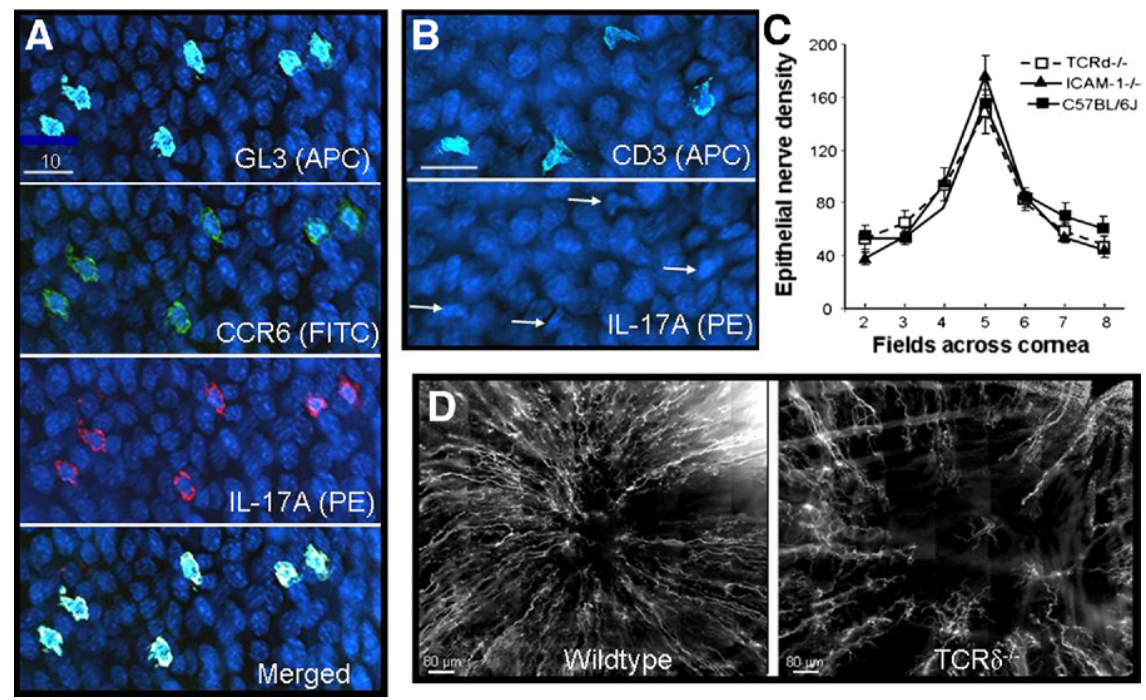

Figure 3. Corneal nerve regeneration in $\mathrm{TCR} \delta^{-/-}$ and ICAM- $1^{-/-}$mice. A: $\mathrm{GL}^{+}$cells (pseudocolor light blue) in the paralimbal epithelium of wild-type mice at 18 hours after central epithelial abrasion. These cells were also positive for CCR6 (green) and IL-17A (red). Blue nuclei of basal epithelial cells stained with DAPI. B: Cornea from a TCR $\delta^{-/-}$mouse at 18 hours after central epithelial abrasion showing $\mathrm{CD}^{+}$cells (pseudocolor light blue) in the paralimbus. The cornea was also stained with anti-IL-17A-PE, but in contrast to wild-type corneas, the $\mathrm{CD}^{+}$cells (arrows in lower panel) were not labeled. C: Epithelial nerve fiber density in seven microscopic fields across the cornea from paralimbus to paralimbus comparing three strains of unwounded, age-matched male mice. No statistical differences were found among the strains. D: Photomontages of the central cornea of a wild-type and an ageand sex-matched TCR $\delta^{-/-}$mouse 96 hours after central epithelial abrasion. Nerves were stained with anti-tubulin III-PE.

\section{Results}

The subbasal plexus of murine corneal nerves was visible in flattened whole mounts stained for $\beta$-tubulin III, and typically exhibited a centripetal pattern of nerves extending from the limbus and converging in a swirl near the center of the cornea (Figure 1). 5,32 A similar pattern has been observed in humans. ${ }^{33}$ Epithelial branches projecting from this plexus into the stratified epithelium were readily visualized en face at the focal plane of the basal epithelial nuclei. In the current study of inflammation and nerve regeneration, animals between 2 and 3 months of age were chosen since this is a period of peak nerve density (Figure 1C). Central corneal epithelial abrasion removes the full thickness of the stratified epithelium, including the subbasal nerves throughout the debrided area (Figure 2A), without direct damage to the underlying corneal stroma or the blood vessels in the limbus. ${ }^{9}$ At 6 hours after abrasion, few neurites were detected within the originally debrided area, but by 24 hours, increased nerve regeneration was seen within the periphery of the original debrided area (Figure 2B). This is a time when epithelial cells migrated as a monolayer to cover the exposed stroma sufficiently to exclude fluorescein applied to the ocular surface ${ }^{34,35}$ (Figure $2 \mathrm{C}$ ). Nerve regeneration progressed to a density of $\sim 19 \%$ of the uninjured cornea within 96 hours, a time when full-thickness epithelial stratification attained pre-injury levels ${ }^{11}$ (Figure 2D). Thus, a distinct temporal dissociation between epithelial restoration and nerve regeneration was evident.

\section{Reduced Inflammation Is Associated with Reduced Corneal Nerve Regeneration}

The inflammatory response to epithelial abrasion appears to be necessary for efficient epithelial healing since experimental conditions that reduce inflammation retard the epithelial migration that covers the abraded area and the epithelial proliferation necessary to restore full stratification. Mice deficient in $\gamma \delta$ T cells have a significantly reduced inflammatory response to central corneal epithelial abrasion (eg, 69\% reduction in neutrophil influx), and the rate of epithelial wound closure is reduced. ${ }^{11,14}$ Although $\gamma \delta$ T cells are sparse and limited to the limbal epithelium in uninjured cornea, they increase in number and migrate in wild-type mice within 24 hours after injury toward the central region of the cornea ${ }^{11}$ where they remain elevated for an extended time beyond full restoration of the epithelium. ${ }^{14}$ In our current studies, the $\mathrm{GL}^{+}$cells (ie, $\gamma \delta$ T cells) stained positively for CCR6 and IL-17A (Figure 3A), and resided in the epithelium nearest the basal epithelial cells. Although TCR $\delta^{-1-}$ mice had some $\mathrm{CD}^{+}$cells in the peripheral epithelium at 24 hours after central epithelial abrasion (Figure 3B), ${ }^{11}$ these cells failed to stain with anti-IL-17A (Figure 3B). Corneal nerve development in the $\mathrm{TCR} \delta^{-1-}$ mice appeared to be comparable to wild-type mice since the nerve density in unwounded corneas was not different from wild-type mice (Figure 3C), but regeneration of nerves after injury was $66 \%$ less $(P<0.001, n=6)$ at 4 days in the $\mathrm{TCR}^{-/-}$mice than in the wild-type mice (Figure 3D, Figure 4, A and B). Reepithelialization was also delayed in the $\mathrm{TCR} \delta^{-1-}$ mice but not as severely as nerve regeneration. There was a $29 \%$ decrease ( $n=4, P<0.01$, Figure $4 C$ ) in epithelial cell density in the abraded area at 4 days post-injury (consistent with our previously published data $\left.{ }^{11}\right)$ in the $\mathrm{TCR} \delta^{-1-}$ mice. Wild-type mice treated before epithelial abrasion with antibody GL3 to acutely deplete $\gamma \delta$ T cells ${ }^{11,36}$ had only $60 \%$ of control regeneration of nerve density $(P<0.001, n=4)$ (Figure 4, A and B). However, administration of GL3 at 14 hours after epithelial abrasion failed to reduce nerve regeneration (Figure 4, A and B). GL3 administration before wounding also reduced the density of epithelial basal cells, but at 14 hours after wounding, GL3 was without effect on this parameter of healing (Figure 4C). Apparently, events within the first 14 hours are important for nerve regeneration and epithelial restoration.

Mice deficient in ICAM-1 have a significantly reduced inflammatory response to corneal epithelial abrasion. ${ }^{14,37}$ Nerve density in uninjured corneas from ICAM-1 ${ }^{-1-}$ mice did not significantly differ from age- and sex-matched wildtype mice (Figure 3C), but neurite regeneration was signif- 


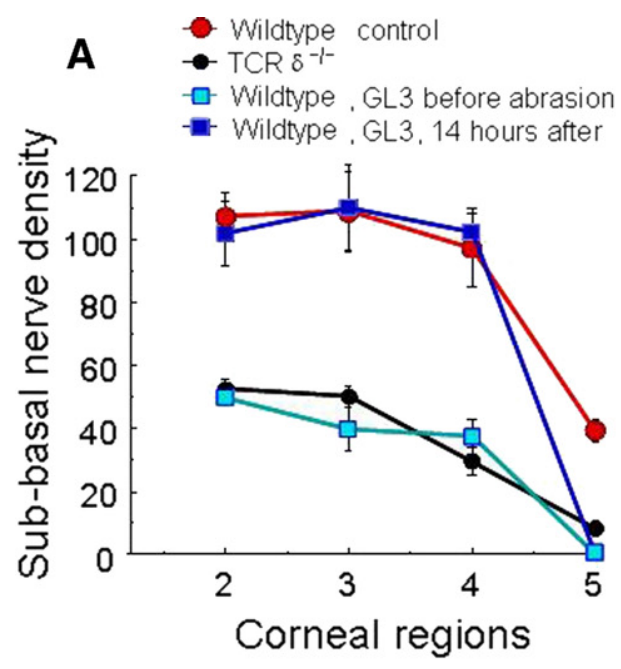

B

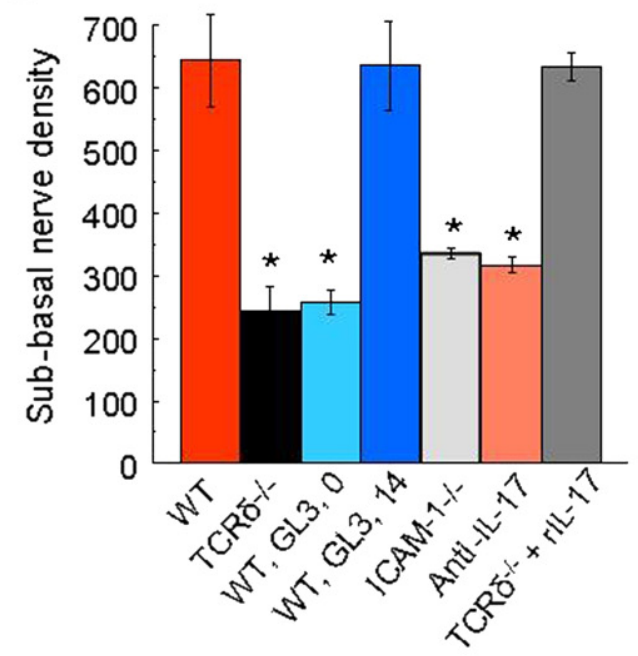

C

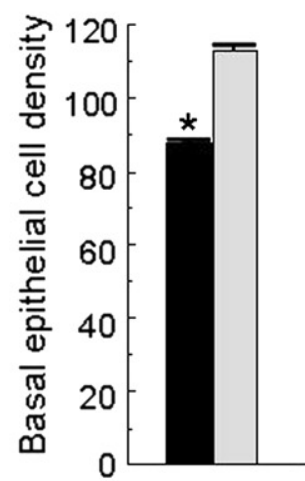

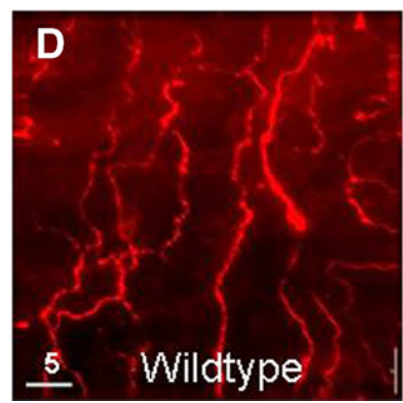
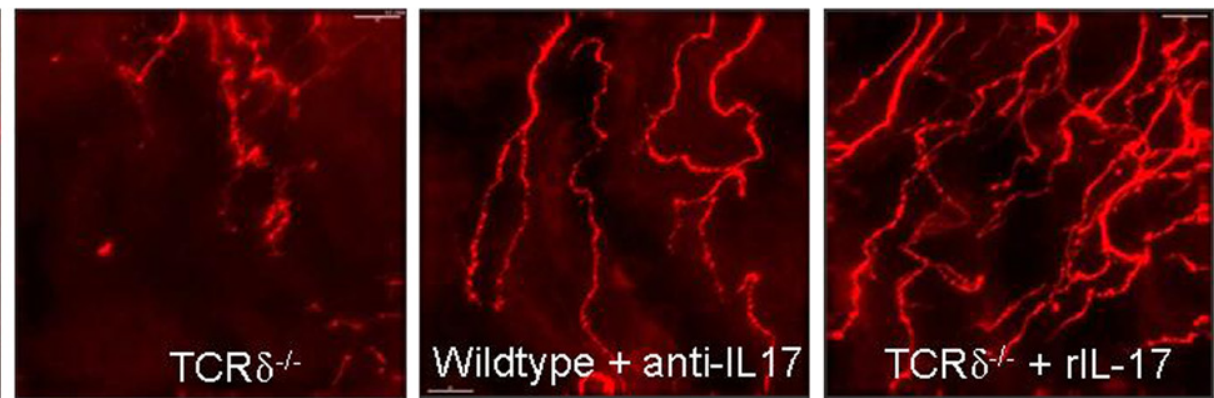

Figure 4. Corneal nerve regeneration in $\mathrm{TCR} \delta^{-/-}$and $\mathrm{ICAM}-1^{-/-}$mice. A: Point-counting analysis of subbasal nerve density in four microscopic fields from paralimbus (field 2) to the corneal center (field 5) at 96 hours after central epithelial abrasion comparing wild-type and TCR $\delta^{-/-}$mice, and wild-type mice treated at different times with antibody GL3 $(n=4$ to 6 , mean \pm SEM). B: Subbasal nerve density graphs of total point-counting values across the cornea at 96 hours after central epithelial abrasion (means \pm SEM, ${ }^{*} P<0.001, n=4$ to 6 for each experimental condition). Experimental conditions: WT, wild-type C57BL/ 6 male mice receiving control nonbinding antibody i.p. before corneal abrasion; TCR $\delta^{-/}, \gamma \delta$ T cell-deficient mice; WT, GL3, 0 indicates WT mice injected i.p. before epithelial abrasion with antibody GL3; WT, GL3, 14 indicates WT mice injected i.p. with antibody GL3 at 14 hours after epithelial abrasion; ICAM-1 ${ }^{-/-}$, mice expressing no full-length or alternatively spliced forms of ICAM- $1^{24}$; Anti-IL-17, mice injected i.p. with anti-IL- 17 before epithelial abrasion; TCR $\delta^{-/-}+$rIL-17 indicates knockout mice receiving i.p. rIL-17 before epithelial abrasion. C: Basal corneal epithelial cell density per field of view in the center of the cornea at 96 hours after central epithelial abrasion from mice receiving GL3 before injury (black bar) and 14 hours after injury (gray bar) (mean \pm SEM, $n=4,{ }^{*} P<0.01$ ). The 14-hour value is not significantly different from untreated mice at 96 hours after injury (mean density of $126 \pm 12$ ). D: Effects of anti-IL-17A antibody given i.p. pre-injury to wild-type mice were analyzed 24 hours after epithelial abrasion, and effects of recombinant IL-17A (rIL-17A) given i.p. pre-injury to TCR $\delta^{-/}-$ mice were analyzed 24 hours after abrasion. These photos show representative images of nerve density in region 3 (see schema in Figure 2).

icantly less at 4 days after epithelial abrasion (Figure 4B). ICAM- $1^{-1-}$ mice had a $56 \%$ reduction $(P<0.001, n=4)$ in nerve regeneration at 96 hours after injury.

Since epithelial $\gamma \delta \mathrm{T}$ cells were positive for $\mathrm{IL}-17$, the potential contribution of this cytokine to wound healing was assessed. Treating wild-type mice by intraperitoneal injection with anti-IL-17 before epithelial abrasion significantly reduced subbasal nerve regeneration at 24 hours after abrasion (34\% reduction, $n=4, P<0.01$, Figure 4D) and at the 96-hour observation time (51\% reduction, $n=4, P<$ 0.001, Figure 4B). Administering recombinant IL-17A i.p. to $\mathrm{TCR}^{-1-}$ mice before epithelial abrasion increased subbasal nerve regeneration at 24 hours after abrasion (Figure 4D) and at the 4-day observation time (Figure 4B).

\section{Platelets Contribute to Corneal Nerve Regeneration}

Antibody GL3 administration at 14 hours after epithelial abrasion failed to reduce nerve recovery, suggesting that the contribution of $\gamma \delta$ T cells to nerve regeneration is early and possibly indirect. Either $\mathrm{TCR} \delta^{-1-}$ or $\mathrm{ICAM}-1^{-1-}$ mice, or specific antibody blockade before corneal wounding with antibody GL3 ${ }^{11}$ or anti-ICAM-1 antibody $Y N 1^{14}$ significantly reduces platelet accumulation in the limbus following central epithelial abrasion. As shown in Figure 5A, platelets were abundant in and around limbal blood vessels at 12 hours after epithelial abrasion in wild-type mice, but platelets were diminished in $\mathrm{TCR} \delta^{-\prime-}$ mice (Figure $5 \mathrm{~B}$ ) and appeared to be largely confined to the vessel lumen. Platelet accumulation and extravasation at 12 hours after wounding was significantly greater in wild-type mice (Figure 5, A and C).

To determine whether platelet accumulation is necessary for efficient corneal nerve regeneration, platelet depletion was induced in wild-type mice by systemic administration of monoclonal antibody to GP1b $\alpha$ given 24 hours before epithelial abrasion. This depletes blood platelets by $\sim 93 \%$ when assessed at 18 hours after epithelial abrasion, with sustained depletion for 4 days with- 

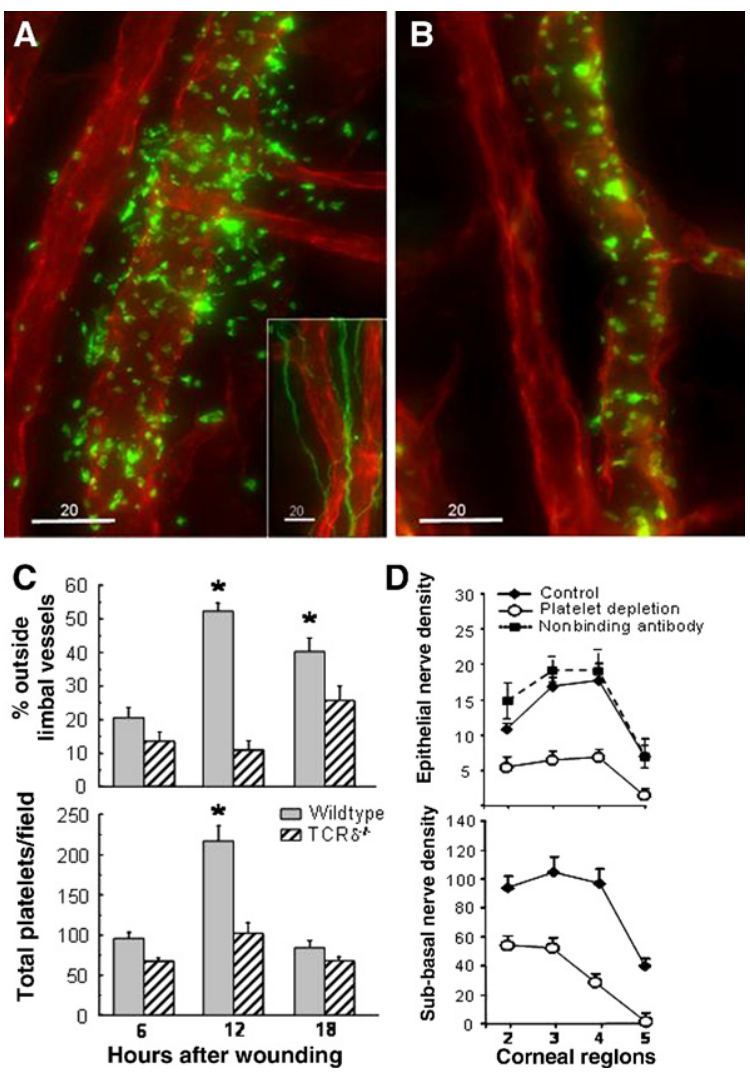

Figure 5. Platelets and corneal nerve regeneration. A: Limbal vessels of a C57BL/6 wild-type male mouse 12 hours after central corneal epithelial abrasion. Vessels were stained with anti-CD31-PE (red), and platelets were stained with anti-CD41-FITC (green). The inset shows limbal vessels (antiCD31-PE, red) and nerves (anti-tubulin III-FITC, green). B: Limbal vessels of $\mathrm{TCR} \delta^{-/-}$male mouse 12 hours after central corneal abrasion (anti-CD31-PE, red, and anti-CD41-FITC, green). C: Platelet distribution in the limbus of two age- and sex-matched strains of mice determined on limbal vessel photomicrographs of deconvolved projected images of $30 \mu \mathrm{m}$ of $z$-stacks collected at 0.5 - $\mu \mathrm{m}$ steps. ${ }^{*} P<0.01, n=4$. D: Wild-type male C57BL/ 6 mice were injected i.p. with anti-GP1ba antibody to deplete blood platelets 24 hours before central corneal epithelial abrasion. Controls were uninjected mice and mice injected with a nonbinding antibody. Whole-mount preparations of corneas were stained with DAPI and anti-tubulin III-PE, and nerve density was evaluated both by counting epithelial nerve branches and point counting subbasal nerves.

out significant changes in other leukocyte numbers. ${ }^{27}$ Corneal nerve recovery at 96 hours after epithelial abrasion was significantly reduced in platelet-depleted mice (Figure 5D). At 24 hours after epithelial abrasion, nerve recovery was $62 \%$ less than controls for epithelial branches $(P<0.001, n=4)$ and $57 \%$ less for subbasal nerves $(P<0.001, n=6)$. Platelet depletion does not reduce the accumulation of $\gamma \delta \mathrm{T}$ cells in the healing corneal epithelium after abrasion, ${ }^{14}$ indicating that $\gamma \delta \mathrm{T}$ cells in the epithelium are insufficient to directly promote corneal nerve regeneration.

The apparent contribution of platelets to corneal nerve regeneration was also investigated by passive transfer of normal platelets into mice deficient in P-selectin, an adhesion molecule necessary for the efficient localization of platelets at an inflammatory site. ${ }^{27,38}$ P-selectin-deficient $\left(P-\mathrm{sel}^{-1-}\right)$ mice without injury exhibit the same level of corneal density as wild-type mice (Figure 6A), but exhibited a 54\% reduction $(P<0.01, n=4)$ in nerve regeneration at 96 hours after epithelial abrasion (Figure 6B), consistent with the observations following systemic platelet depletion. Platelets isolated from C57BL/6 wild-type mice of the same background as the $\mathrm{P}-\mathrm{sel}^{-1-}$ mice were transferred i.v. to P-sel ${ }^{-1-}$ mice 30 minutes before corneal epithelial abrasion. $\mathrm{P}-\mathrm{sel}^{-1-}$ mice receiving the wildtype platelets exhibited significantly greater nerve recovery at 96 hours after injury than $\mathrm{P}-$ sel $^{-1-}$ receiving i.v. injection of vehicle (Figure 6B). Epithelial branches of subbasal nerves revealed a $63 \%$ increase $(P<0.01, n=$ $4)$, and subbasal nerve fiber analysis revealed a $48 \%$ increase $(P<0.01, n=4)$. These observations indicate a role for platelets in corneal nerve regeneration.

\section{Neutrophils in Inflammation-Enhanced Corneal Nerve Regeneration}

Our previous studies of the inflammatory response to corneal abrasion revealed that either $\gamma \delta$ T cell deficiency or systemic platelet depletion significantly reduces neutrophil accumulation in the corneal limbus and stroma, and P-selectin-deficient mice exhibit markedly reduced neutrophil accumulation in the cornea that is significantly corrected by passive transfer of wild-type platelets. ${ }^{27}$ Though excessive neutrophil accumulation may be associated with enhanced epithelial injury, ${ }^{37}$ the possibility that neutrophils are necessary for the inflammation-enhanced corneal nerve regeneration was assessed. Mice receiving either anti-Ly6G (to deplete neutrophils) or anti$\mathrm{GP} 1 \mathrm{~b} \alpha$ (to deplete platelets) had significantly less corneal nerve recovery at 24 hours after corneal abrasion than control mice (Figure 7A). Previous studies have shown that platelet depletion markedly reduces neutrophil accumulation, and neutrophil depletion markedly reduces platelet accumulation after epithelial abrasion. ${ }^{27}$ Since anti-Ly6G and anti-GP1b $\alpha$ antibodies are specific
A

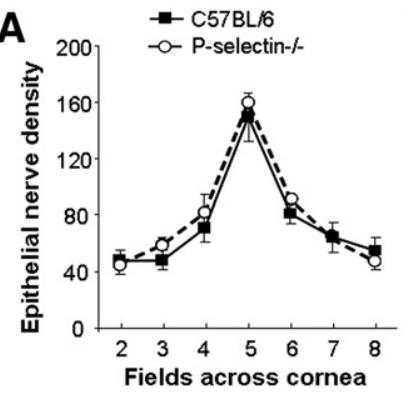

\section{B}

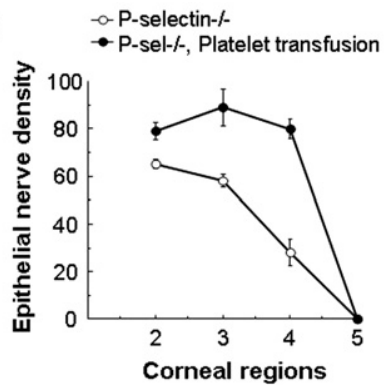

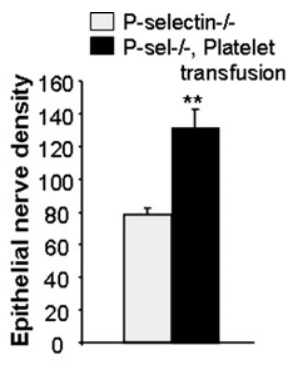

Figure 6. Passive transfer of wild-type platelets into P-selectin-deficient mice. A: Density of corneal epithelial nerve branches was quantified in uninjured wild-type and P-selectin-deficient mice $(n=4)$. B: Density of subbasal nerves was analyzed in regions of the cornea at 96 hours after central epithelial abrasion in P-selectin-deficient mice with and without passive intravenous transfer of platelets 24 hours before corneal wounding $(n=4)$. Total counts of epithelial nerves across the corneas at 96 hours in P-selectin-deficient mice with and without passive transfer of platelets. ( $\left.{ }^{*} P<0.01, n=4\right)$ 
A
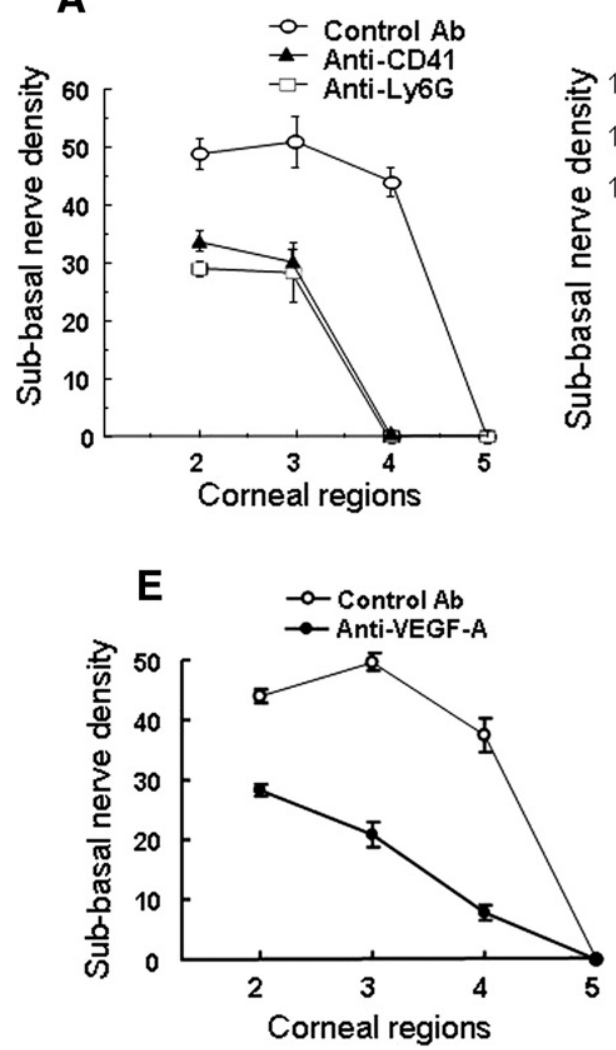

B $\quad-a$ Control Ab

$\rightarrow$ Anti-VEGF -A Anti-Ly6G

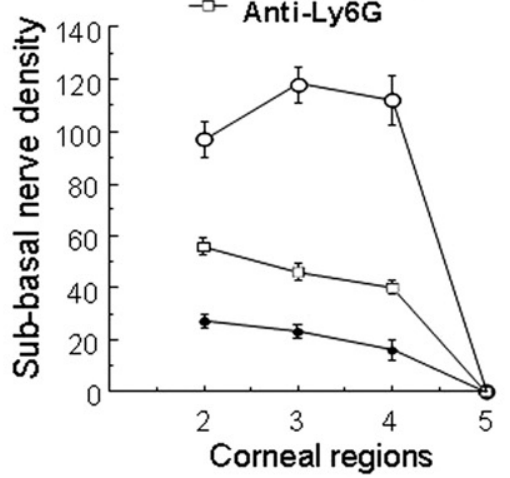

C

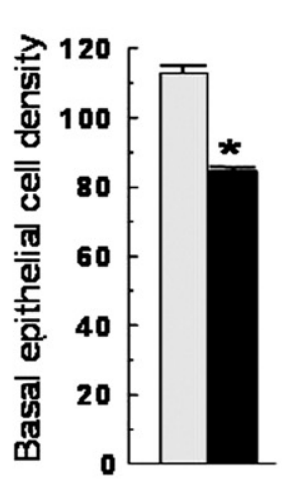

D

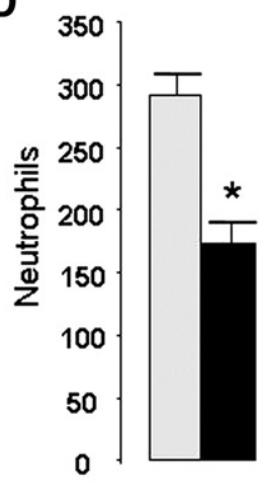

\section{$\mathbf{F}$}

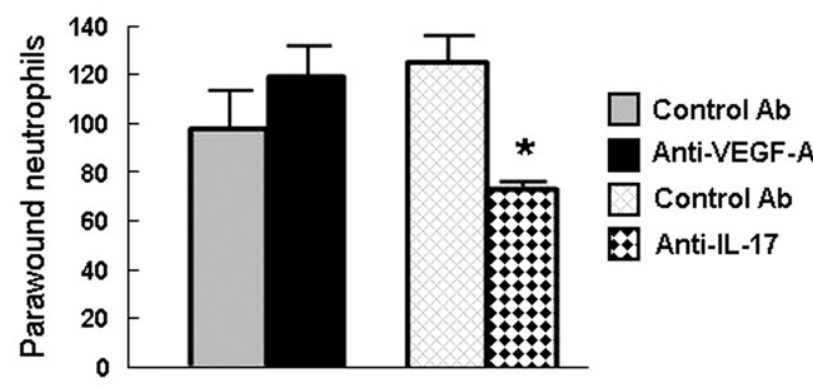

Figure 7. Neutrophils and VEGF-A in corneal nerve regeneration. A: Density of corneal subbasal nerves was analyzed at 24 hours after central epithelial abrasion in wild-type mice receiving i.p. control nonbinding antibody (Control Ab), anti-GP1b $\alpha$ (ie, to induce platelet depletion), or anti-Ly6G (ie, to induce neutrophil depletion) before corneal wounding $(n=4)$. B: Density of corneal subbasal nerves was analyzed at 96 hours after central epithelial abrasion in wild-type mice receiving i.p. control antibody, anti-VEGF-A, or anti-Ly6G before central epithelial abrasion. C: Basal epithelial cell density at 96 hours after central epithelial abrasion in mice receiving i.p. control antibody (gray bar) or anti-VEGF-A (black bar, $n=4,{ }^{*} P<0.01$ ) before epithelial abrasion. D: Neutrophils per field of view in parawound corneal stroma at 12 hours after central epithelial abrasion in mice receiving i.p. the control antibody (gray bar) or anti-VEGF-A (black bar, $n=$ $\left.6,{ }^{*} P<0.01\right)$. E: Topical application of anti-VEGF-A or control IgG every 4 hours for 24 hours after corneal epithelial abrasion in wild-type mice plotting subbasal nerve density in fields of the cornea from paralimbus to center at 24 hours after wounding (curves significantly different, $P<0.01, n=4$ ). F: Topical application of anti-VEGF-A or control IgG every 4 hours for 12 hours after corneal epithelial abrasion in wild-type mice plotting neutrophils in four randomly selected fields of view within the original wound margin (ie, field 3, schema in Figure 2B); or topical application of anti-IL-17 or control IgG to a second set of mice using the same protocol $\left(n=6,{ }^{*} P<0.01\right)$.

for the respective cell types, and induce selective depletion of these cells from the blood, ${ }^{27}$ the colocalization of neutrophils and platelets in the cornea is apparently a necessary condition for enhanced nerve regeneration.

In the extravascular space, platelets remained mostly within $30 \mu \mathrm{m}$ of limbal vessels, but neutrophils migrated to the center of the cornea within hours of injury. ${ }^{9}$ Neutrophils were rarely seen within the epithelium but were prominently located immediately below the subbasal nerves (Figure 8, A and E). Neutrophils are known to carry VEGF-A in their granules, ${ }^{39-43}$ and VEGF is known to exhibit a trophic effect on nerve growth. ${ }^{44-49}$ Mice receiving systemic administration of anti-VEGF-A had $85 \%$ less $(n=4, P<0.001)$ corneal nerve recovery at 96 hours after epithelial abrasion than mice receiving the control antibody (Figure 7B). Systemic injection of anti-VEGF-A has reported anti-inflammatory activity ${ }^{50}$ but appeared in this model to be more effective in reducing nerve regeneration at this time than it was in reducing the early influx of neutrophils (40\% reduction, $n=4, P<0.01$ ) (Figure 7D). The anti-VEGF-A treatment reduced by less than 20\% $(P<0.01, n=4)$ the basal epithelial cell density at 96 hours after wounding (Figure 7C).

To test the local effect of anti-VEGF-A, mice with corneal abrasions on both eyes were treated topically with anti-VEGF-A in one eye and control IgG in the contralateral eye. Treatments were applied every 4 hours for 24 hours, and corneas were collected and analyzed for nerve regeneration in that region of the cornea and for neutrophils arriving beneath the original wound edge. Consistent with the systemic administration of antiVEGF-A, nerve regeneration was significantly retarded (60.5\% reduction, $n=6, P<0.01$ ) in the treated eye compared to the contralateral eye (Figure 7E), but in contrast to systemic treatment, topical anti-VEGF-A failed to reduce the number of neutrophils arriving at the wound edge at 12 hours after epithelial abrasion (Figure 7F). These observations support the idea that local VEGF-A is critical to early nerve regeneration but not neutrophil emigration. Local IL-17, however, does appear to participate in neutrophil recruitment since the arrival of neutrophils at the wound edge 12 hours after wounding was significantly reduced by topical application of anti-IL-17 (Figure 7F). 

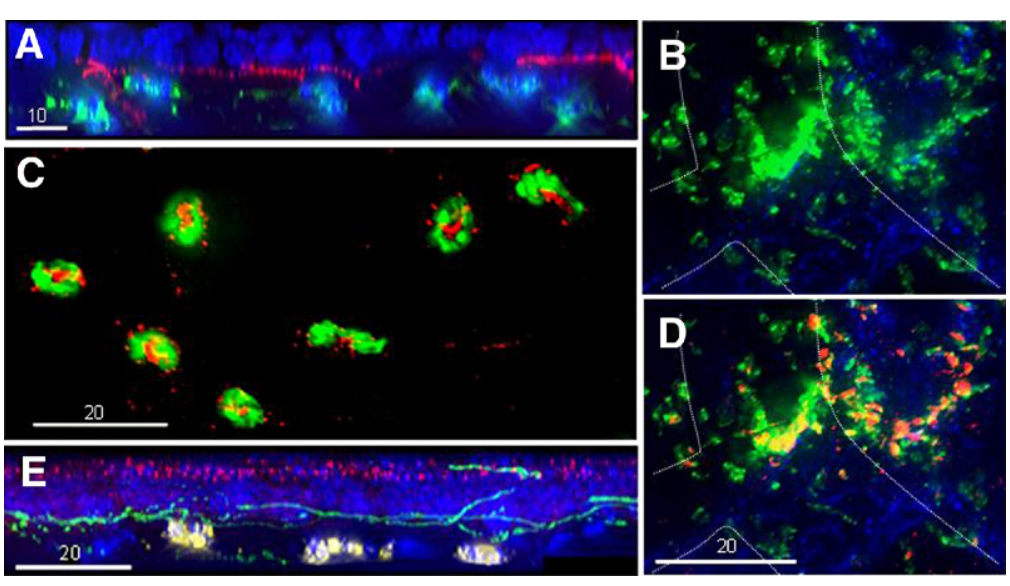

Figure 8. Photomicrographs of murine corneal tissue after central epithelial abrasion. Neutrophils in the cornea: (A) An orthogonal view of the region of the original wound margin at 12 hours after injury generated from a deconvolved $30-\mu$ m-deep $z$-stack collected at $0.5-\mu \mathrm{m}$ steps revealing the positional relationship between basal epithelial nuclei (blue, DAPI) above the subbasal nerves (red, anti-tubulin III), and neutrophils (green, anti-Gr-1FITC) below. C: Neutrophils in a deconvolved image of a single $0.5-\mu \mathrm{m}$-deep focal plane in the subbasal region of the original wound margin at 12 hours after epithelial abrasion, revealing antiVEGF-A antibody binding (red) associated with the neutrophils. E: An orthogonal view of a region of the original wound margin after 24 hours generated from a deconvolved $30-\mu$ m-deep $z$-stack collected at $0.5-\mu \mathrm{m}$ steps revealing the positional relationship between epithelial nuclei (blue, DAPI) with staining in the outer layers of the epithelium with anti-VEGF-A (red), subbasal nerves (green, anti-tubulin III), and neutrophils (yellow, anti-Gr-1). Platelets in the cornea: (B) Limbus at 12 hours after epithelial abrasion showing platelets (green, anti-GP1ba) and limbal vessel outlined by hatched line (staining of anti-CD31 not shown for optimal view of anti-GP1ba staining). D: Same field of view as B, revealing the staining pattern of anti-VEGF-A (red/yellow) and anti-GP1ba (green).
A possible link between neutrophils/platelets and corneal VEGF was supported by immunocytology that revealed staining for VEGF-A in the emigrated neutrophils (Figure $8 \mathrm{C}$ ) and platelets (Figure 8, B and D). VEGF-A levels in corneal tissue peaked at 12 hours after corneal abrasion in wild-type mice (Figure 9A). In wild- type mice following anti-Ly6G-induced neutrophil depletion, VEGF-A and platelet localization in the limbus were reduced in the cornea at 12 hours after injury (Figure 9, B and $\mathrm{C})$. $\mathrm{TCR}^{-1-}$ and P-sel ${ }^{-1-}$ mice also had reduced VEGF-A levels in corneal tissue at 12 hours after injury (Figure 9B), consistent with the previously shown reduc-
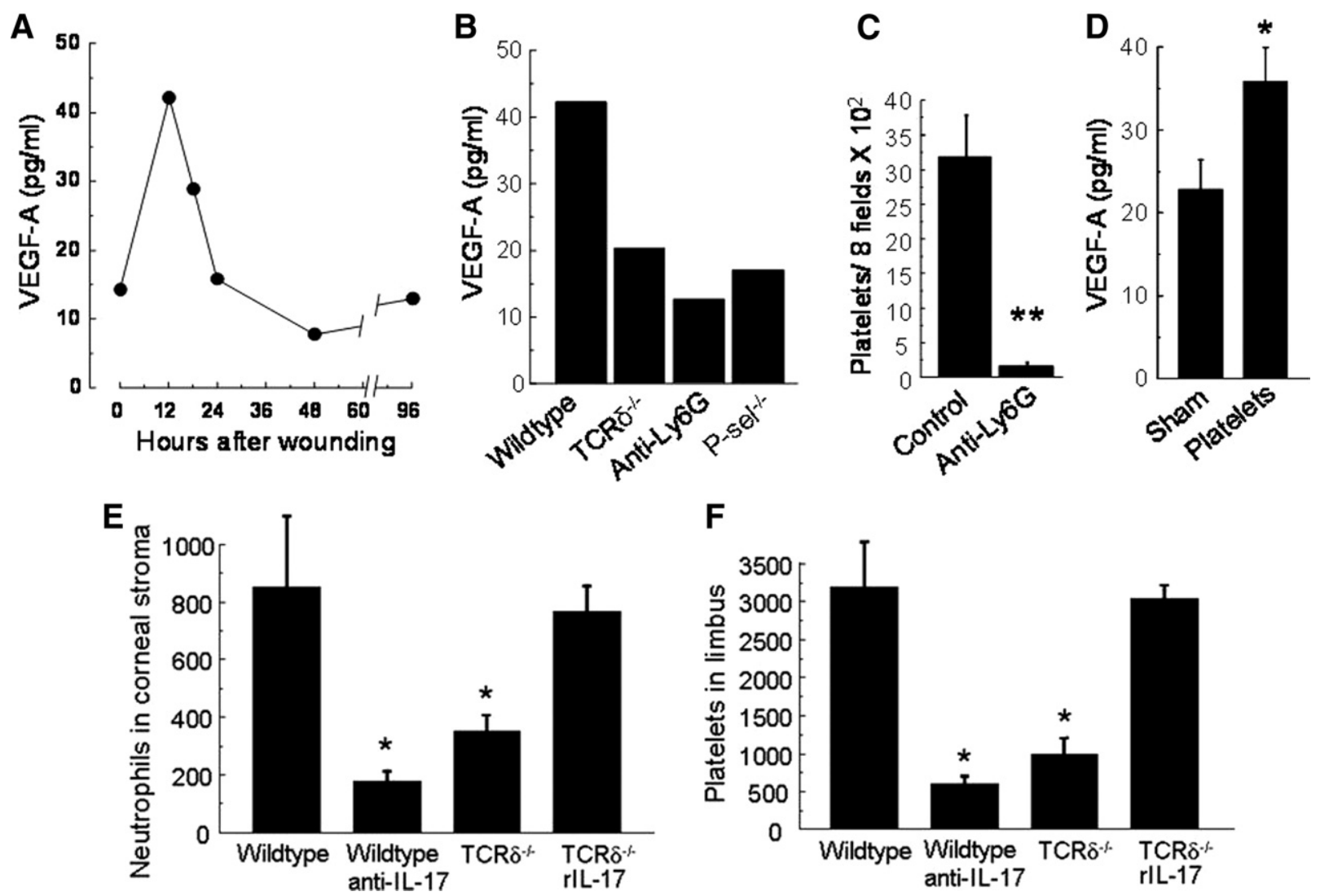

Figure 9. VEGF-A detected by ELISA in corneas following central epithelial abrasion. A: Extracts of six corneas per time point after central epithelial abrasion in wild-type mice were pooled, and each pool was analyzed by ELISA for VEGF-A. B: Extracts of six corneas at 12 hours after central epithelial abrasion were pooled and analyzed for VEGF-A. Comparisons are shown of wild-type with TCR $\delta^{-/-}$, P-sel ${ }^{-/-}$, and wild-type mice treated before injury with anti-Ly6G to deplete circulating neutrophils. C: Effects of anti-Ly6G on the accumulation of platelets in the limbus of corneas at 12 hours after central epithelial abrasion $(n=4$, $\left.{ }_{* *}^{*} P<0.001\right)$. D: $\mathrm{P}-\mathrm{sel}^{-/-}$mice were either sham treated or given wild-type platelets i.v. before central epithelial abrasion. At 18 hours following abrasion, corneas were collected, and VEGF-A was determined by ELISA, $n=3$ separate experiments for each condition, ${ }^{*} P<0.01$. Neutrophils in the parawound and paralimbal stromal regions $(\mathbf{E})$ and platelets in the limbus $(\mathbf{F})$ at 12 hours after epithelial abrasion comparing wild-type, wild-type treated with anti-IL-17 i.p. before wounding, $\mathrm{TCR} \delta^{-1-}$ mice, and TCR $\delta^{-1-}$ mice receiving rIL-17 i.p. before wounding ( $n=4$ for each condition, $P<0.01$ compared with wild-type control). 
tion in neutrophil and platelet response in these mice. ${ }^{11}$ P-sel ${ }^{-1-}$ mice receiving passive transfer of wild-type platelets exhibited not only increased corneal nerve recovery (Figure 6B) and neutrophil accumulation, ${ }^{27}$ but also significantly increased VEGF-A detected in the abraded corneas by ELISA (Figure 9D).

The observed changes in nerve regeneration after depleting or supplementing IL-17 in this model (Figure 4B) likely reflect changes in neutrophil/platelet mobilization. As shown in Figure 9, E and F, systemic administration of anti-IL-17 reduced both neutrophil and platelet accumulation at 12 hours after epithelial abrasion, and systemic administration of rlL-17A before wounding in $\mathrm{TCR} \delta^{-1-}$ mice resulted in tissue levels of neutrophils and platelets similar to those in wild-type mice.

\section{Discussion}

Corneal epithelium heals rapidly following abrasion, returning to unwounded basal epithelial density and depth of stratification within a few days, ${ }^{11}$ but the stability of the healed epithelium appears to be uncertain, with observed erosions at later times. ${ }^{51}$ In contrast to the epithelium, the subbasal nerve plexus is $<20 \%$ of its unwounded density at the time when the epithelium initially appears fully healed. Marked delays in nerve healing appear to be true in humans as well. ${ }^{52-54}$ Given the known trophic effect of the subbasal nerves on the epithelium, ${ }^{55-57}$ sustained health of wounded corneal epithelium may depend on substantial nerve regeneration.

Our results indicate that corneal nerve regeneration following central corneal epithelial abrasion is positively influenced by the inflammatory process. Components of the inflammatory cascade critical to this beneficial effect include $\gamma \delta \mathrm{T}$ cells in the epithelium, influx of neutrophils into the stroma beneath the regenerating nerves, and accumulation of platelets in the limbus. These events occur within the first 12 to 24 hours following epithelial abrasion. The major influx and contribution of these cells apparently occur within this time frame when very early nerve regrowth can be detected, and epithelial wound closure is nearing completion. Targeted depletion of $\gamma \delta \mathrm{T}$ cells, neutrophils, or platelets is sufficient to result in some delay in epithelial wound closure, ${ }^{11,14,27}$ but corneal nerve recovery at 4 days is markedly reduced.

$\gamma \delta \mathrm{T}$ cells are resident in small numbers within the limbus of the normal cornea. ${ }^{11}$ After corneal abrasion, they increase significantly in the limbal, paralimbal, and parawound areas of the epithelium and remain elevated in numbers for up to 2 weeks. ${ }^{14}$ They also increase in the stroma near the limbal blood vessels especially early after wounding, preceding substantial increases in their number in the epithelium. In ICAM-1-deficient mice (ie, animals with no full-length or alternatively spliced forms of ICAM-1), ${ }^{24} \gamma \delta$ T cells accumulate in the stroma near limbal vessels but fail to migrate into the healing epithelium. ${ }^{14}$ It seems that normal expression of ICAM-1 by the corneal epithelium is necessary for $\gamma \delta$ T cell localization in the epithelium. The observation of significantly delayed nerve regeneration in ICAM-1-deficient mice suggests that localization of $\gamma \delta$ T cells in the epithelium is important to their contribution to healing. However, wild-type mice depleted of platelets exhibit normal accumulation of $\gamma \delta \mathrm{T}$ cells in the epithelium following abrasion, ${ }^{14}$ but as shown in the present study, platelet depletion significantly delayed nerve regeneration. These observations suggest the $\gamma \delta$ T cells that accumulate in the cornea are insufficient to directly promote nerve regrowth.

The $\gamma \delta \mathrm{T}$ cells in the cornea may function predominantly to induce rapid neutrophil and platelet accumulation, consistent with known activity of the $\mathrm{IL}-17^{+}$subsets of $\gamma \delta$ T cells. ${ }^{16,18,22}$ Though neutrophils may be detrimental to wound healing in some instances and locations (eg, epidermal re-epithelialization ${ }^{1}$ ), evidence for a significant role in tissue healing comes from studies of corneal epithelial wounds where depletion of leukocytes is associated with delayed re-epithelialization $n^{9,27,58}$ and enhanced spinal cord injury with diminished neuronal functions. ${ }^{2} \mathrm{TCR} \delta^{-1-}$ mice or wild-type mice treated before corneal epithelial abrasion with antibody GL3 in the model used in the current report exhibit $>65 \%$ reduction in both neutrophils and platelets ${ }^{11}$ within the first 18 hours after injury. The recruitment of neutrophils is an established, IL-17-dependent function of some $\gamma \delta$ T cell subsets, ${ }^{16}$ but the recruitment of platelets is a new observation. In corneal tissue, the recruitment of platelets and neutrophils appears to be interdependent, ${ }^{27}$ but the mechanism for this interdependence is not clear. Platelet P-selectin appears to be necessary since the deficient colocalization of neutrophils and platelets in the limbus of P-selectin-deficient mice is partially restored by the passive intravenous transfer of isolated wild-type platelets. ${ }^{27}$

Temporal and spatial assessment of neutrophils localizes them very near the subbasal nerve plexus when early nerve regeneration into the original wound is evident. This places neutrophils at a substantial distance from the limbal vessels, the site of transmigration from the blood. Their migration to the wound edge occurs within the stroma and appears to be in contact with the keratocyte network within the orthogonally arranged collagen layers of the anterior cornea. ${ }^{59}$ Neutrophils directly below the subbasal nerves stain positively for VEGF, consistent with the established presence of VEGF stores in mature neutrophils. ${ }^{39-43}$ ELISA-detected VEGF in the healing corneas at 18 hours after injury is substantially influenced by neutrophil influx since neutrophil depletion markedly diminished VEGF levels. An apparent contribution of VEGF to nerve regeneration was indicated in mice treated systemically with anti-VEGF antibody before corneal wounding or treated topically with anti-VEGF immediately following injury, and the degree of inhibition was substantially greater than anti-VEGF-induced delay in epithelial wound closure. The established trophic effect of VEGF on nerve growth, ${ }^{45-49}$ including studies of neurite outgrowth of trigeminal ganglion cultures, ${ }^{44}$ supports an interpretation that VEGF is critical to corneal nerve regeneration. Our data are consistent with the possibility that neutrophils acutely provide VEGF necessary for early nerve regeneration. In vitro stimulation of murine neutrophils induces rapid release of prestored VEGF. ${ }^{43}$ 
The avascular nature of the cornea is due in part to intrinsic mechanisms that limit availability of VEGF in the corneal tissue, ${ }^{60,61}$ and it is well-known that lesions to the cornea induced by toxic substances or foreign bodies embedded in the cornea induce neovascularization that is prominently dependent on VEGF ${ }^{62}$ likely supplied by inflammatory cells. ${ }^{43,63}$ Anti-VEGF strategies are of interest in preventing neovascularization. ${ }^{64}$ However, with corneal lesions such as epithelial abrasion with damage to the corneal nerves, neovascularization is not evident, and as we and others have observed, ${ }^{65,66}$ anti-VEGF delays to some extent re-epithelialization. The more pronounced inhibitory effect of anti-VEGF, as discussed above, is on nerve regeneration.

Our current experiments indicate that local IL-17 participates in early arrival of neutrophils at the wound edge, but systemic effects of the experimental IL-17 depletion and restoration may indicate an influence of broader mechanisms on eye inflammation. Although the $\gamma \delta$ T cells in the cornea within the first 18 hours after injury are positive for IL-17, and mice deficient in $\gamma \delta \mathrm{T}$ cells lack cells positive for IL-17, the use of systemic administration of antibodies and recombinant IL-17 leaves open the clear resolution of whether the $\gamma \delta \mathrm{T}$ cells in the cornea are the dominant contributors of IL-17 effects. Systemic increases in IL-17 may augment neutrophil emigration at inflammatory sites. ${ }^{67}$ Systemic depletion and restoration of IL-17 may act at potentially several sites including nerves, ${ }^{44}$ limbal vessels, ${ }^{67,68}$ and bone marrow ${ }^{69}$ to influence the $\gamma \delta \mathrm{T}$ cell-dependent inflammatory cascade. Accumulation of neutrophils and platelets within the first 14 hours after injury could significantly affect additional healing processes such as macrophage accumulation with longer-term production of nerve growth factors. ${ }^{70}$

In summary, our results demonstrate that $\gamma \delta \mathrm{T}$ cells, IL-17, neutrophils, platelets, and VEGF are necessary for efficient corneal nerve regeneration following epithelial abrasion. $\gamma \delta$ T cells are required for the influx of neutrophils and platelets, but appear insufficient to directly promote nerve regrowth. The early rise of VEGF in the wounded cornea is significantly dependent on neutrophils and platelets, and $\mathrm{VEGF}^{+}$neutrophils are in proximity to very early regenerating neurites. Anti-VEGF administered systemically before injury or topically after injury markedly retards nerve regeneration. These results document a beneficial role for the $\gamma \delta \mathrm{T}$ cell-dependent inflammatory response to corneal epithelial abrasion.

\section{References}

1. Dovi JV, He LK, DiPietro LA: Accelerated wound closure in neutrophildepleted mice. J Leukoc Biol 2003, 73:448-455

2. Stirling DP, Liu S, Kubes P, Yong VW: Depletion of Ly6G/Gr-1 leukocytes after spinal cord injury in mice alters wound healing and worsens neurological outcome. J Neurosci 2009, 29:753-764

3. Muller LJ, Marfurt CF, Kruse F, Tervo TM: Corneal nerves: structure, contents and function. Exp Eye Res 2003, 76:521-542

4. Kubilus JK, Linsenmayer TF: Developmental corneal innervation: interactions between nerves and specialized apical corneal epithelial cells. Invest Ophthalmol Vis Sci 2010, 51:782-789
5. Leiper LJ, Ou J, Walczysko P, Kucerova R, Lavery DN, West JD Collinson JM: Control of patterns of corneal innervation by Pax6. Invest Ophthalmol Vis Sci 2009, 50:1122-1128

6. Garcia-Hirschfeld J, Lopez-Briones LG, Belmonte C: Neurotrophic influences on corneal epithelial cells. Exp Eye Res 1994, 59:597-605

7. Mackie IA: Role of the corneal nerves in destructive disease of the cornea. Trans Ophthalmol Soc UK 1978, 98:343-347

8. Araki K, Ohashi Y, Kinoshita S, Hayashi K, Kuwayama Y, Tano Y: Epithelial wound healing in the denervated cornea. Curr Eye Res 1994, 13:203-211

9. Li Z, Burns AR, Smith CW: Two waves of neutrophil emigration in response to corneal epithelial abrasion: distinct adhesion molecule requirements. Invest Ophthalmol Vis Sci 2006, 47:1947-1955

10. Jin Y, Shen L, Chong EM, Hamrah P, Zhang Q, Chen L, Dana MR: The chemokine receptor CCR7 mediates corneal antigen-presenting cell trafficking. Mol Vis 2007, 13:626-634

11. Li Z, Burns AR, Rumbaut RE, Smith CW: Gamma delta T cells are necessary for platelet and neutrophil accumulation in limbal vessels and efficient epithelial repair after corneal abrasion. Am J Pathol 2007, 171:838-845

12. Lee EJ, Rosenbaum JT, Planck SR: Epifluorescence intravital microscopy of murine corneal dendritic cells. Invest Ophthalmol Vis Sci 2010, 51:2101-2108

13. Yamagami S, Hamrah P, Miyamoto K, Miyazaki D, Dekaris I, Dawson T, Lu B, Gerard C, Dana MR: CCR5 chemokine receptor mediates recruitment of $\mathrm{MHC}$ class II-positive Langerhans cells in the mouse corneal epithelium. Invest Ophthalmol Vis Sci 2005, 46:1201-1207

14. Byeseda SE, Burns AR, Dieffenbaugher S, Rumbaut RE, Smith CW, Li Z: ICAM-1 is necessary for epithelial recruitment of gammadelta T cells and efficient corneal wound healing. Am J Pathol 2009, 175:571-579

15. Havran W L, Jameson JM: Epidermal T cells and wound healing. J Immunol 2010, 184:5423-5428

16. Bonneville M, O'Brien RL, Born WK: Gammadelta T cell effector functions: a blend of innate programming and acquired plasticity. Nat Rev Immunol 2010, 10:467-478

17. Hayday AC: Gammadelta T cells and the lymphoid stress-surveillance response. Immunity 2009, 31:184-196

18. O'Brien RL, Roark CL, Born WK: IL-17-producing gammadelta T cells. Eur J Immunol 2009, 39:662-666

19. Jameson JM, Cauvi G, Sharp LL, Witherden DA, Havran WL: Gammadelta $T$ cell-induced hyaluronan production by epithelial cells regulates inflammation. J Exp Med 2005, 201:1269-1279

20. Alexander M, Daniel T, Chaudry $I H$, Choudhry MA, Schwacha MG: T cells of the gammadelta T-cell receptor lineage play an important role in the postburn wound healing process. J Burn Care Res 2006, 27:18-25

21. Kapsenberg ML: Gammadelta T cell receptors without a job. Immunity 2009, 31:181-183

22. Martin B, Hirota K, Cua DJ, Stockinger B, Veldhoen M: Interleukin17-producing gammadelta $T$ cells selectively expand in response to pathogen products and environmental signals. Immunity 2009, 31: 321-330

23. Pietschmann K, Beetz S, Welte S, Martens I, Gruen J, Oberg HH, Wesch D, Kabelitz D: Toll-like receptor expression and function in subsets of human gammadelta $\mathrm{T}$ lymphocytes. Scand J Immunol 2009, 70:245-255

24. Robker RL, Collins RG, Beaudet AL, Mersmann HJ, Smith CW: Leukocyte migration in adipose tissue of mice null for icam-1 and mac-1 adhesion receptors. Obes Res 2004, 12:936-940

25. Brake DK, Smith EO, Mersmann H, Smith CW, Robker RL: ICAM-1 expression in adipose tissue: effects of diet-induced obesity in mice. Am J Physiol Cell Physiol 2006, 291:C1232-C1239

26. Daley JM, Thomay AA, Connolly MD, Reichner JS, Albina JE: Use of Ly6G-specific monoclonal antibody to deplete neutrophils in mice. J Leukoc Biol 2008, 83:64-70

27. Li Z, Rumbaut RE, Burns AR, Smith CW: Platelet response to cornea abrasion is necessary for acute inflammation and efficient re-epithelialization. Invest Ophthalmol Vis Sci 2006, 47:4794-4802

28. Goodman T, Lefrancois L: Intraepithelial Iymphocytes. Anatomical site, not $\mathrm{T}$ cell receptor form, dictates phenotype and function. J Exp Med 1989, 170:1569-1581

29. Reinders ME, Sho M, Izawa A, Wang P, Mukhopadhyay D, Koss KE, Geehan CS, Luster AD, Sayegh MH, Briscoe DM: Proinflammatory functions of vascular endothelial growth factor in alloimmunity. J Clin Invest 2003, 112:1655-1665 
30. Smith E, Stark MA, Zarbock A, Burcin TL, Bruce AC, Vaswani D, Foley $P$, Ley K: IL-17A inhibits the expansion of IL-17A-producing T cells in mice through "short-loop" inhibition via IL-17 receptor. J Immunol 2008, 181:1357-1364

31. Cho JS, Pietras EM, Garcia NC, Ramos RI, Farzam DM, Monroe HR, Magorien JE, Blauvelt A, Kolls JK, Cheung AL, Cheng G, Modlin RL, Miller LS: IL-17 is essential for host defense against cutaneous Staphylococcus aureus infection in mice. J Clin Invest 2010, 120:1762-1773

32. $\mathrm{Yu} C Q$, Rosenblatt MI: Transgenic corneal neurofluorescence in mice: a new model for in vivo investigation of nerve structure and regeneration. Invest Ophthalmol Vis Sci 2007, 48:1535-1542

33. Patel SV, McLaren JW, Hodge DO, Bourne WM: Confocal microscopy in vivo in corneas of long-term contact lens wearers. Invest Ophthalmol Vis Sci 2002, 43:995-1003

34. Fini ME, Stramer BM: How the cornea heals: cornea-specific repair mechanisms affecting surgical outcomes. Cornea 2005, 24:S2-S11

35. Nagasaki T, Zhao J: Centripetal movement of corneal epithelial cells in the normal adult mouse. Invest Ophthalmol Vis Sci 2003, 44:558566

36. Yamamoto S, Russ F, Teixeira HC, Conradt P, Kaufmann SH: Listeria monocytogenes-induced gamma interferon secretion by intestina intraepithelial gamma/delta T Iymphocytes. Infect Immun 1993, 61 : 2154-2161

37. Li Z, Burns AR, Smith CW: Lymphocyte function-associated antigen1-dependent inhibition of corneal wound healing. Am J Pathol 2006, 169:1590-1600

38. Frenette PS, Johnson RC, Hynes RO, Wagner DD: Platelets roll on stimulated endothelium in vivo: an interaction mediated by endothelial P-selectin. Proc Natl Acad Sci U S A 1995, 92:7450-7454

39. Taichman NS, Young S, Cruchley AT, Taylor P, Paleolog E: Human neutrophils secrete vascular endothelial growth factor. J Leukoc Bio 1997, 62:397-400

40. Scapini P, Morini M, Tecchio C, Minghelli S, Di Carlo E, Tanghetti E, Albini A, Lowell C, Berton G, Noonan DM, Cassatella MA: CXCL1/ macrophage inflammatory protein-2-induced angiogenesis in vivo is mediated by neutrophil-derived vascular endothelial growth factor-A. $\mathrm{J}$ Immunol 2004, 172:5034-5040

41. Scapini P, Calzetti F, Cassatella MA: On the detection of neutrophilderived vascular endothelial growth factor (VEGF). J Immunol Methods 1999, 232:121-129

42. Gaudry M, Bregerie O, Andrieu V, El Benna J, Pocidalo MA, Hakim J: Intracellular pool of vascular endothelial growth factor in human neutrophils. Blood 1997, 90:4153-4161

43. Gong Y, Koh DR: Neutrophils promote inflammatory angiogenesis via release of preformed VEGF in an in vivo corneal model. Cell Tissue Res 2010, 339:437-448

44. Yu CQ, Zhang M, Matis KI, Kim C, Rosenblatt MI: Vascular endothelial growth factor mediates corneal nerve repair. Invest Ophthalmol Vis Sci 2008, 49:3870-3878

45. Zhu Y, Jin K, Mao XO, Greenberg DA: Vascular endothelial growth factor promotes proliferation of cortical neuron precursors by regulating E2F expression. FASEB J 2003, 17:186-193

46. Liu Y, Figley S, Spratt SK, Lee G, Ando D, Surosky R, Fehlings MG: An engineered transcription factor which activates VEGF-A enhances recovery after spinal cord injury. Neurobiol Dis 2010, 37:384-393

47. Jin K, Zhu Y, Sun Y, Mao XO, Xie L, Greenberg DA: Vascular endothelial growth factor (VEGF) stimulates neurogenesis in vitro and in vivo. Proc Natl Acad Sci U S A 2002, 99:11946-11950

48. Sondell M, Sundler F, Kanje M: Vascular endothelial growth factor is a neurotrophic factor which stimulates axonal outgrowth through the flk-1 receptor. EurJ Neurosci 2000, 12:4243-4254

49. Sondell M, Lundborg G, Kanje M: Vascular endothelial growth factor has neurotrophic activity and stimulates axonal outgrowth, enhancing cell survival and Schwann cell proliferation in the peripheral nervous system. J Neurosci 1999, 19:5731-5740

50. Schonthaler HB, Huggenberger R, Wculek SK, Detmar M, Wagner EF: Systemic anti-VEGF treatment strongly reduces skin inflammation in a mouse model of psoriasis. Proc Natl Acad Sci U S A 2009, 106:21264-21269

51. Pal-Ghosh S, Pajoohesh-Ganji A, Brown M, Stepp MA: A mouse model for the study of recurrent corneal epithelial erosions: alpha9beta1 integrin implicated in progression of the disease. Invest Ophthalmol Vis Sci 2004, 45:1775-1788
52. Darwish T, Brahma A, O'Donnell C, Efron N: Subbasal nerve fiber regeneration after LASIK and LASEK assessed by noncontact esthesiometry and in vivo confocal microscopy: prospective study. J Cataract Refract Surg 2007, 33:1515-1521

53. Moilanen JA, Holopainen JM, Vesaluoma MH, Tervo TM: Corneal recovery after lasik for high myopia: a 2-year prospective confocal microscopic study. Br J Ophthalmol 2008, 92:1397-1402

54. Erie JC, McLaren JW, Hodge DO, Bourne WM: Recovery of corneal subbasal nerve density after PRK and LASIK. Am J Ophthalmol 2005 140:1059-1064

55. Nagano T, Nakamura M, Nakata K, Yamaguchi T, Takase K, Okahara A, Ikuse T, Nishida T: Effects of substance P and IGF-1 in cornea epithelial barrier function and wound healing in a rat model of neurotrophic keratopathy. Invest Ophthalmol Vis Sci 2003, 44:3810-3815

56. Nishida T, Yanai R: Advances in treatment for neurotrophic keratopathy. Curr Opin Ophthalmol 2009, 20:276-281

57. Ferrari G, Chauhan SK, Ueno H, Nallasamy N, Gandolfi S, Borges L, Dana R: A novel mouse model for neurotrophic keratopathy: trigeminal nerve stereotactic electrolysis through the brain. Invest Ophthalmol Vis Sci 2010, doi:10.1167/iovs.10-5688.

58. Gan L, Fagerholm P, Kim HJ: Effect of leukocytes on corneal cellular proliferation and wound healing. Invest Ophthalmol Vis Sci 1999 , 40:575-581

59. Petrescu MS, Larry CL, Bowden RA, Williams GW, Gagen D, Li Z, Smith CW, Burns AR: Neutrophil interactions with keratocytes during corneal epithelial wound healing: a role for CD18 integrins. Invest Ophthalmol Vis Sci 2007, 48:5023-5029

60. Ambati BK, Nozaki M, Singh N, Takeda A, Jani PD, Suthar T, Albuquerque RJ, Richter E, Sakurai E, Newcomb MT, Kleinman ME, Caldwell RB, Lin Q, Ogura Y, Orecchia A, Samuelson DA, Agnew DW, St Leger J, Green WR, Mahasreshti PJ, Curiel DT, Kwan D, Marsh H, Ikeda S, Leiper LJ, Collinson JM, Bogdanovich S, Khurana TS, Shibuya M, Baldwin ME, Ferrara N, Gerber HP, De Falco S, Witta J, Baffi JZ, Raisler BJ, Ambati J: Corneal avascularity is due to soluble VEGF receptor-1. Nature 2006, 443:993-997

61. Cursiefen C, Chen L, Saint-Geniez M, Hamrah P, Jin Y, Rashid S, Pytowski B, Persaud K, Wu Y, Streilein JW, Dana R: Nonvascular VEGF receptor 3 expression by corneal epithelium maintains avascularity and vision. Proc Natl Acad Sci U S A 2006, 103:11405-11410

62. Amano S, Rohan R, Kuroki M, Tolentino M, Adamis AP: Requirement for vascular endothelial growth factor in wound- and inflammationrelated corneal neovascularization. Invest Ophthalmol Vis Sci 1998 39:18-22

63. Cursiefen C, Chen L, Borges LP, Jackson D, Cao J, Radziejewski C D'Amore PA, Dana MR, Wiegand SJ, Streilein JW: VEGF-A stimulates lymphangiogenesis and hemangiogenesis in inflammatory neovascuIarization via macrophage recruitment. J Clin Invest 2004, 113:10401050

64. Bock F, Onderka J, Rummelt C, Dietrich T, Bachmann B, Kruse FE, Schlotzer-Schrehardt U, Cursiefen C: Safety profile of topical VEGF neutralization at the cornea. Invest Ophthalmol Vis Sci 2009, 50: 2095-2102

65. Kim EC, Lee WS, Kim MS: The inhibitory effects of bevacizumab eyedrops on NGF expression and corneal wound healing in rats Invest Ophthalmol Vis Sci 2010, 51:4569-4573

66. Kim TI, Chung JL, Hong JP, Min K, Seo KY, Kim EK: Bevacizumab application delays epithelial healing in rabbit cornea. Invest Ophthalmol Vis Sci 2009, 50:4653-4659

67. Roussel L, Houle F, Chan C, Yao Y, Berube J, Olivenstein R, Martin JG, Huot J, Hamid Q, Ferri L, Rousseau S: IL-17 promotes p38 MAPK-dependent endothelial activation enhancing neutrophil recruitment to sites of inflammation. J Immunol 2010, 184:4531-4537

68. Rollin S, Lemieux C, Maliba R, Favier J, Villeneuve LR, Allen BG, Soker S, Bazan NG, Merhi Y, Sirois MG: VEGF-mediated endothelial P-selectin translocation: role of VEGF receptors and endogenous PAF synthesis. Blood 2004, 103:3789-3797

69. von Vietinghoff S, Ley K: IL-17A controls IL-17F production and maintains blood neutrophil counts in mice. J Immunol 2009, 183:865-873

70. Kigerl KA, Gensel JC, Ankeny DP, Alexander JK, Donnelly DJ, Popovich PG: Identification of two distinct macrophage subsets with divergent effects causing either neurotoxicity or regeneration in the injured mouse spinal cord. J Neurosci. 2009, 29:13435-13444 